\title{
Alloy Design and Processing Design of Magnesium Alloys Using 2nd Phases
}

\author{
R.F. DECKER, ${ }^{1,5}$ T.D. BERMAN ${ }^{2}$ V.M. MILLER ${ }^{3}$ J.W. JONES ${ }^{2}$ \\ T.M. POLLOCK, ${ }^{4}$ and S.E. LEBEAU ${ }^{1}$ \\ 1.-Thixomat/NanoMAG, Livonia, USA. 2.-The University of Michigan, Ann Arbor, USA. \\ 3.-North Carolina State University, Raleigh, USA. 4.-University of California Santa Barbara, \\ Santa Barbara, USA. 5.—e-mail: rdecker@nanomag.us
}

\begin{abstract}
Two phases dominate the performance of commercial $\mathrm{Mg}$ alloys: (1) $\beta \mathrm{Mg}_{17} \mathrm{Al}_{12}$ and (2) porosity. Alloy design and process design to optimize the morphology of the first and to minimize the second are discussed. Second phase $\beta$ can be designed to improve tensile strength, fatigue strength, toughness, texture, formability and corrosion resistance of $\mathrm{Mg}$ alloys. Processing is applied to refine the grain size, to array this phase in micron sizes at grain boundaries, and to further precipitate this phase in nanometer arrays within the grains. Therein, the 2 nd phase $\beta$ plays the following roles: (1) retarding grain growth, (2) randomizing texture, (3) Hall-Petch hardening, (4) Orowan hardening, and (5) moderating corrosion. Porosity is a detrimental 2nd phase common to cast $\mathrm{Mg}$ alloys in the form of gas or voids; its control being essential to engineering applications. Porosity can be diminished by sub-liquidus molding with high-velocity/high-pressure injection and then eliminated by subsequent hot deformation.
\end{abstract}

\section{BACKGROUND ON Mg-Al-Zn ALLOYS AND COMMERCIAL DOMINANCE}

The cast $\mathrm{AM}(\mathrm{Mg}-\mathrm{Al})$ and $\mathrm{AZ}(\mathrm{Mg}-\mathrm{Al}-\mathrm{Zn})$ alloys dominate the world market for $\mathrm{Mg}$ alloys to the total of more than $50 \%$ of the commercial tonnage. $\beta$ is the most prevalent 2nd phase in $\mathrm{Mg}$ alloys. New $\mathrm{Mg}$ alloys have not proliferated in commerce over the last 50 years, as have steels and $\mathrm{Al}$ alloys. One reason is the higher cost of alternate alloying elements, another reason being the reluctance of major $\mathrm{Mg}$ alloy recyclers to contaminate their $\mathrm{Mg}$ $\mathrm{Al}-\mathrm{Zn}$ melts with other alloying elements. Hence, Mg-Al-Zn alloy producers can recover about $1 / 3$ value/\# of primary ingot for their scrap, but not as much with new compositions.

\section{Cast Structures}

The majority of the tonnage of $\mathrm{Mg}$ alloys is ascast, wherein structure and properties depend on casting parameters. Nominal yield strengths are about $140 \mathrm{MPa}$, with $5 \%$ elongation and fatigue limit of 20-50 MPa. These conventional die-cast alloys are not heat-treatable because of blistering from porosity, nor age-hardenable due to $>10 \mu \mathrm{m}$ eutectic intermetallic arrays. Their porosity degrades mechanical properties such as ductility, toughness and fatigue resistance; nor is vigorous hot working feasible. Due to shear band formation in large grains, hot deformation is limited to many small reductions of about $20 \%$ with interposed annealing treatments. A larger reduction causes hot cracking (see Fig. 1).

Thus, refinement of the 2nd phase microstructure by processing is desirable to remedy these shortcomings.

\section{REFINEMENT OF $\beta$, POROSITY AND GRAIN SIZE DURING CASTING}

One effective processing approach is to refine the microstructure by foregoing the die casting's $80^{\circ} \mathrm{C}$ superheat above the alloy liquidus temperature. Sub-liquidus semi-solid injection molding by Thixomolding ${ }^{\circledR}$ utilizes high pressures and fast injection at about $5-10 \%$ solids and $>1.5 \mathrm{~m} / \mathrm{s}$ to afford fill times of $0.05 \mathrm{~s}$ which makes for a fast cooling rate of about $50-100^{\circ} \mathrm{C} / \mathrm{s}$ and reduced shrinkage porosity. The "hot nozzle" practice minimizes temperature 
(b)

(a)
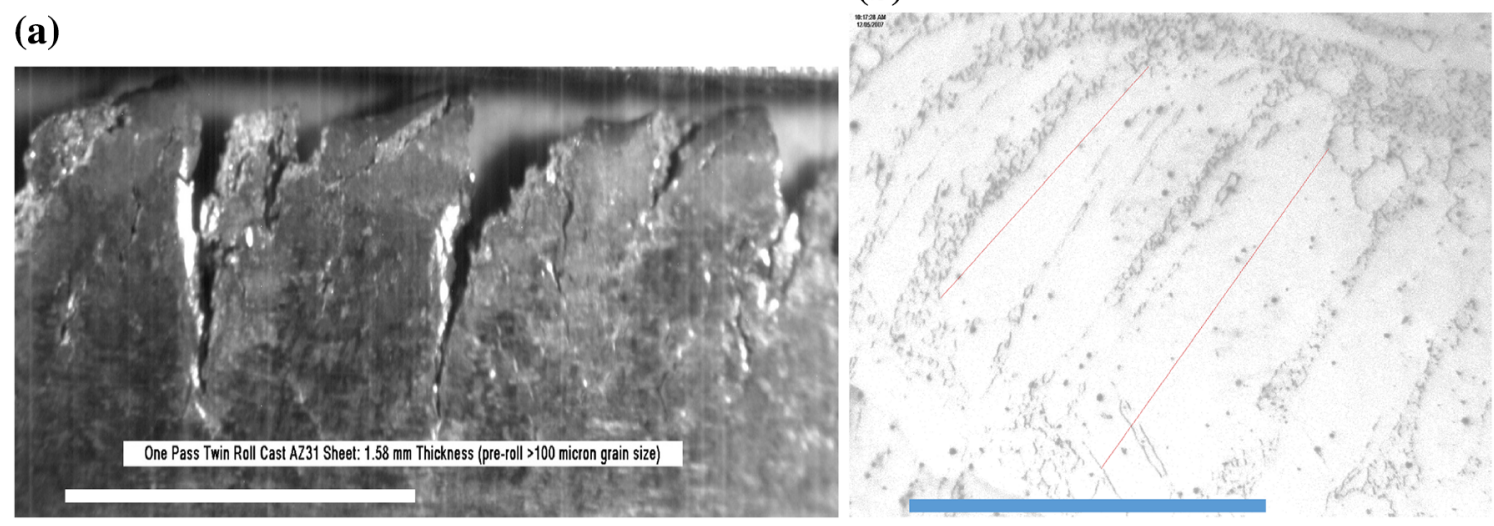

Fig. 1. Formation of weak fine-grained shear bands in large grain AZ31 casting during hot rolling reduction of $50 \%$ in one pass and resultant edge cracking. (a) Hot cracking (bar $25 \mathrm{~mm}$ ). (b) Shear bands in large grains (bar $50 \mu \mathrm{m}$ ).

(a)

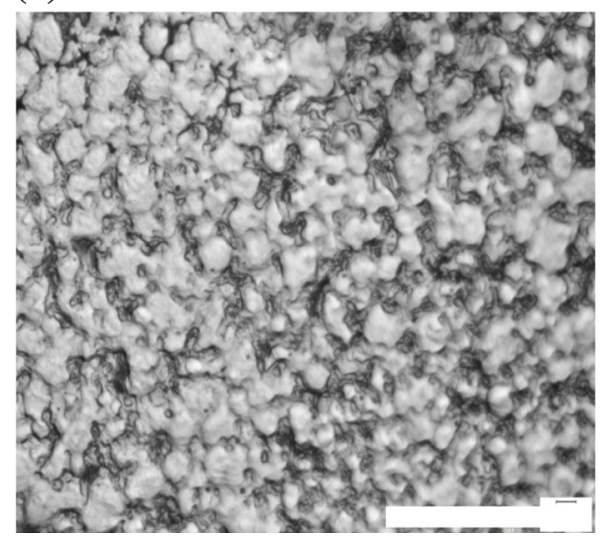

(b)

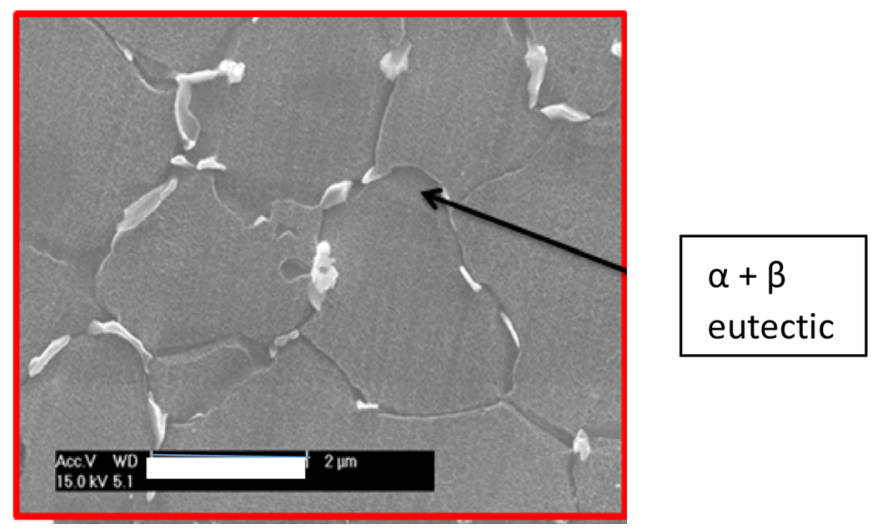

Fig. 2. (a) Optical (bar $50 \mu \mathrm{m}$ ) and (b) electron micrographs (bar $2 \mu \mathrm{m}$ ) of as-Thixomolded Mg-Al-Zn alloys with $<1 \mu \mathrm{m} \beta$ phase at grain boundaries.

drop from the hot slurry barrel to the part inlet, thus further reducing porosity throughout the part. Argon protection in the barrel and vacuum in the die obviate oxide pick-up. By this commercial practice, fine grain size averaging $4-6 \mu \mathrm{m}$, random texture and porosity of $<1.5 \%$ are attained over section thicknesses of $0.6-25 \mathrm{~mm}$ (Fig. 2). The intermetallic divorced-eutectic $\beta$ phase size is reduced to average size of $0.5-2 \mu \mathrm{m}$ and the alloy matrix is left supersaturated in $\mathrm{Al}$ (reporting only 4 of the equilibrium $10 \% \beta$ in a 6 wt.\% $\mathrm{Al}$ alloy in AZ61).

Of the $32 \mathrm{Mg}$ alloys and composites that have been Thixomolded, ${ }^{1}$ the optimum combination of castability (fluid and non-sticky), strength, ductility and corrosion resistance emerged in the $\mathrm{Mg}$ base containing $5-9 \%$ Al plus $0-1 \% \mathrm{Zn}$. The common Thixomoldings are in AM60, AZ61 and AZ91 with compositions listed in Table I. In a project with Dead Sea magnesium, AM70-TH was designed for ductility and AXJ810 for creep resistance. These
Table I. Composition of Thixomolded Mg alloys

\begin{tabular}{|c|c|c|c|c|}
\hline Alloy & Al & Zn & $\mathbf{C a}$ & Sr \\
\hline AM60 & 6 & - & - & - \\
\hline AZ61 & 6 & 0.5 & - & - \\
\hline AZ70-TH & 7 & 0.5 & - & - \\
\hline AZ91 & 9 & 0.7 & - & - \\
\hline AXJ810-TH & 8 & - & 1 & 0.3 \\
\hline
\end{tabular}

compositions can be Thixomolded into complex 3D net shapes and are heat-treatable. All thrive with 2nd phase $\beta$ wherein volume $\%$ increases as $\mathrm{Al}$ increases, reaching about $10 \%$ by volume $\beta$ at 9 wt. $\%$ Al.

Herein lies the first role of 2 nd phase $\beta$-participating in a low-temperature eutectic reaction that affords as-cast a fine grain size $\alpha$ matrix encapsulated by $\mu \mathrm{m}$-sized $\beta$ particles. 


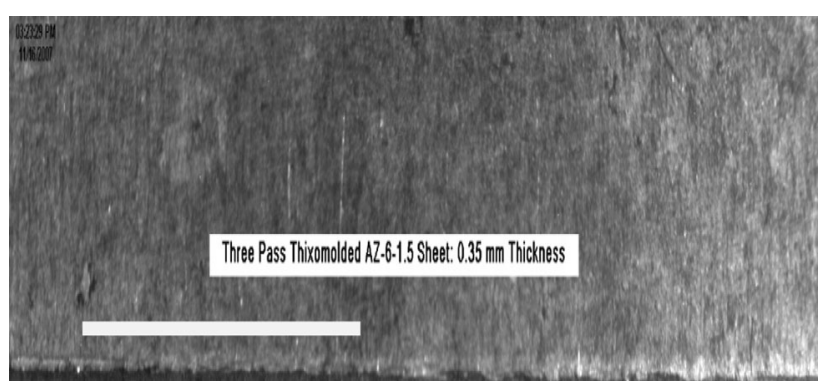

Fig. 3. Lack of edge cracking in 3 passes of $50 \%$ reduction each in hot rolling of Thixomolded AZ6Al-1.5Zn (bar $25 \mathrm{~mm}$ ).

\section{REFINEMENT OF $\beta$ AND POROSITY DURING THERMOMECHANICAL PROCESSING AFTER THIXOMOLDING (TTMP)}

This is effective as another remedy. ${ }^{2,3}$ Reductions of $50 \%$ in one pass by hot rolling are practiced without cracking (Fig. 3). Therein, medium temperature, high strain and high strain rate deformation create microstructures that are generated by the presence of $\beta$ phase. Also, hot pressing, forging and blow forming are enabled. Porosity is eliminated. The roles of $\beta$ are:

1. $\beta$ restrains grain growth. The as-molded $0.7-\mu \mathrm{m}$ eutectic $\beta$ seen in Fig. 2 in AZ61 pins the grain boundaries during sub-solvus deformation and heating, invoking the Zener mechanism. ${ }^{4}$ The same role is played by $1-\mu \mathrm{m}$ to $2-\mu \mathrm{m} \beta$ in AXJ810. ${ }^{5}$ By retaining fine grains, twinning is minimized, shear banding and associated nucleation of hot cracks are avoided, and Hall-Petch strengthening is enhanced by grain refinement according to:

$$
\Delta \sigma \approx d^{-1 / 2}
$$

where $\sigma$ is strength and $d$ is grain diameter.

2. $\beta$ strengthens by dispersion hardening. The supersaturated as-Thixomolded $\alpha$ matrix precipitates nanometer $\beta$ dispersoids during TTMP. The vol. $\% \beta$ can increase from $4 \%$ to $8 \%$ during processing, which reduces interparticle distance. ${ }^{4}$ The nanometer $\beta$ particles are fine enough and hard enough to enable Orowan strengthening according to:

$$
\Delta \sigma \approx 0.13 G b / \lambda \ln r / b
$$

where $r$ is particle radius, $\lambda$ is interparticle distance, $G$ is shear modulus and $b$ is Burger's number.

Strength is boosted when particle size is decreased and interparticle distance is decreased. The co-generation of dislocations and precipitating $\beta$ during hot deformation increase dislocation density and decrease $\beta$ size. Such $\beta$ particles have been observed in both

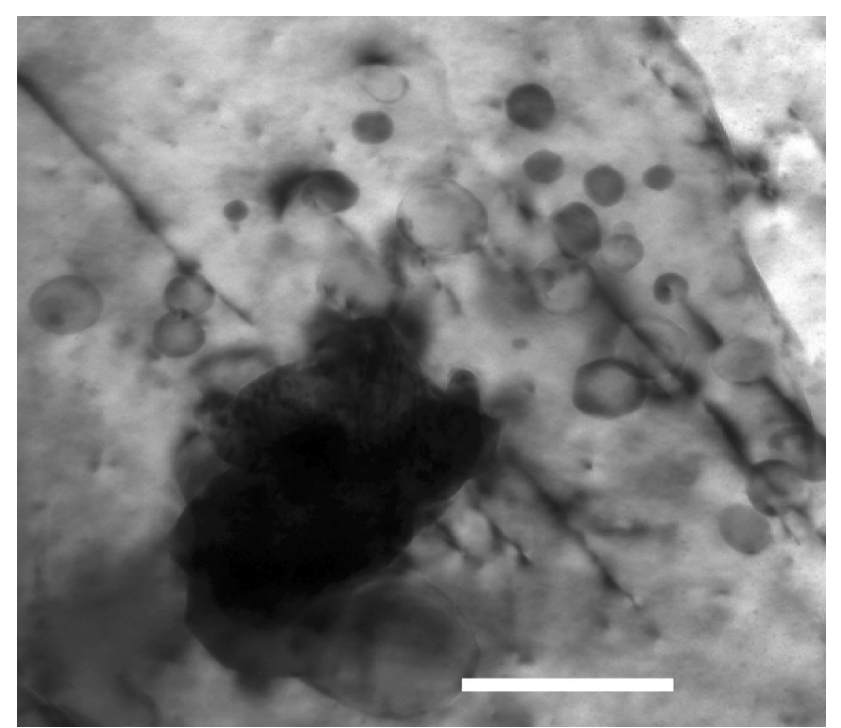

Fig. 4. Intragranular $\beta$ and dislocations in Thixomolded AZ70-TH hot-rolled $50 \%$ (bar $250 \mathrm{~nm}$ ).

spherical (Fig. 4) and acicular morphologies. Their number (vol.\%) is more than doubled in hot deformation of $0.5 / \mathrm{s},{ }^{4}$ compared to the asThixomolded state.

3. $\beta$ substitutes for rare earth elements (RE) to afford low near-basal textures. RE additions to Mg alloys are well established as a means to achieve low texture. ${ }^{4,5}$ As an alternative mechanism, the presence of $\beta$ arrayed at grain boundaries during hot deformation nucleates randomized $0.5-\mu \mathrm{m} \alpha$ matrix grains around the $\beta$ particles by dynamic recrystallization (see the mechanisms shown in Fig. 5). ${ }^{4}$ Low texture $(\mathrm{MRD}=3.5)$ is generated upon further recrystallization (Fig. 6) and grain size is reduced to $2 \mu \mathrm{m}$ by restraint of growth by this $\beta$ array. The reduced texture rendered by the mechanism of Fig. 5 decreases the $r$ and $\Delta r$ values, indicating greater stretchability and less earing during sheet forming (Table II). In this AZ61 alloy, the subsequent deformation is still dominated by basal slip, being attributable to randomized basal plane orientations, not to more prismatic or pyramidal slip. ${ }^{4}$

In deformation studies of Thixomolded AXJ810$\mathrm{TH}$, Miller ${ }^{5}$ found supersaturation to $11.6 \% \mathrm{Al}$ in the as-Thixomolded matrix. This excess, together with the array of $\beta$ particles at grain boundaries, made for a weak texture of 3.4 MRD after 0.7 strain-an effect stronger than with either factor alone. The presence of the coarse $\beta$ particles promoted increased grain orientation spread, geometrically necessary dislocations and a more diffuse deformation texture. In contrast to the case of AZ61, ${ }^{4}$ the $\mathrm{Ca}$ and $\mathrm{Sr}$ in AXJ810 strengthened against basal slip and 
(a)

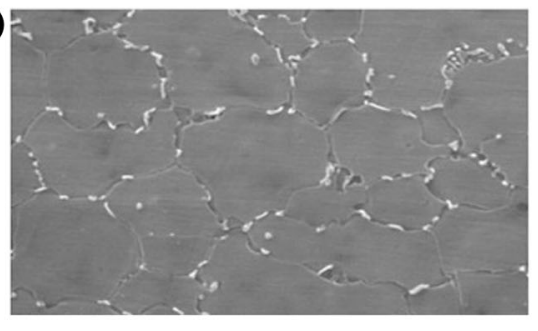

$5 \mu \mathrm{m}$

(c)

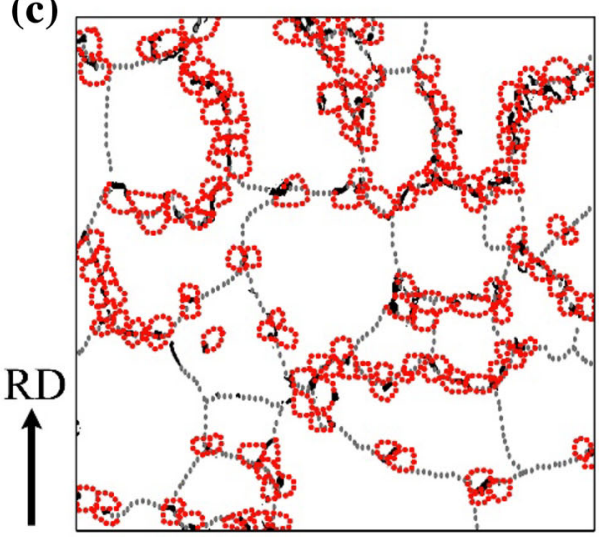

(b)

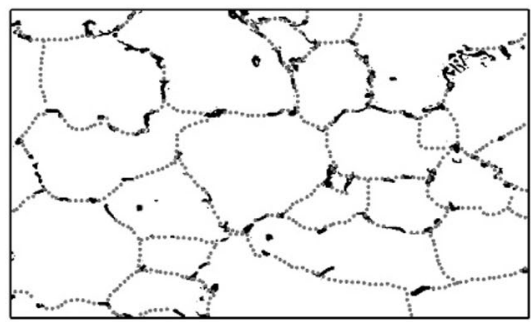

(d)

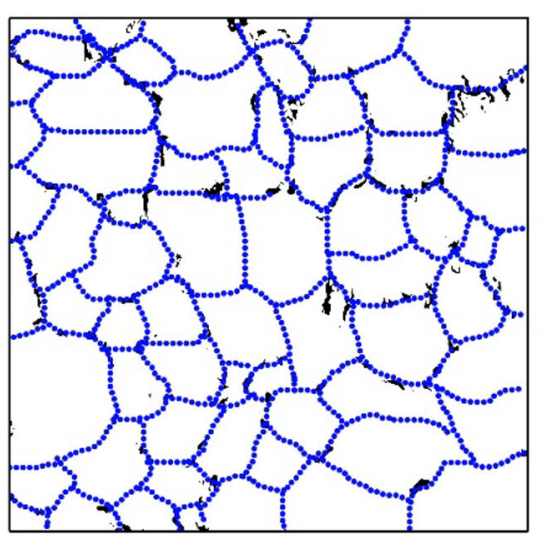

Fig. 5. During TTMP, Zener pinning at high-angle grain boundaries by $\beta$ particles provides new orientations in nearby $\alpha$ grains. (a) SEM image, (b) the as-Thixomolded microstructure, (c) the as-rolled microstructure showing the preferential recrystallization near $\beta$ particles and the prior grain boundaries, and (d) the fully recrystallized microstructure with grains pinned by $\beta$ phase. (Reprinted from Ref. 4).
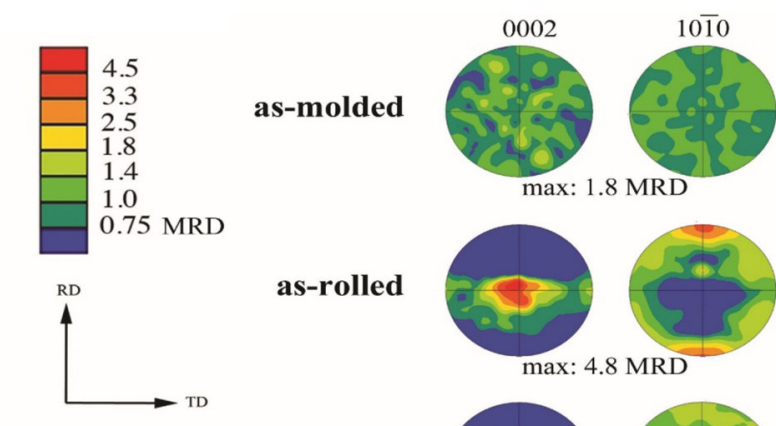

rolled $+558 \mathrm{~K}\left(285^{\circ} \mathrm{C}\right) / 10 \mathrm{~min}$

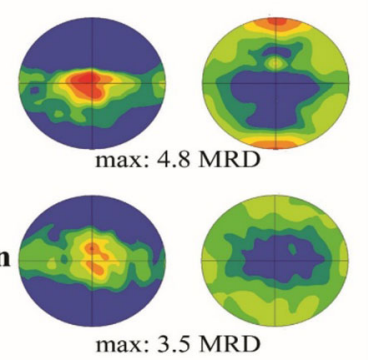

Fig. 6. Evolution of texture through Thixomolding and TTMP of AZ61. (Reprinted from Ref. 4).

weakened prismatic slip. A short anneal of 5 min at $300^{\circ} \mathrm{C}$ after TTMP provided a low texture of 3.1 in this creep-resistant alloy. The fine AXJ810 Thixomolded grain structure that also contains coarse intermetallic particles is resistant to shear banding and twinning during deformation. This structure also enables the development of strong intragranular orientation gradients during compression. ${ }^{5}$
The reduced texture rendered by the mechanism of Fig. 5 decreases the Lankford $r$ and $\Delta r$ values, indicating greater stretchability and less earing during sheet forming (Table VI). The $r$ value is the ratio of plastic strain in-plane to that in-thickness.

4. $\beta$ Morphology Controls Corrosion. $\beta$ is cathodic to the $\alpha$ matrix phase. Thus, potential differences between $\beta$ and $\alpha$, area ratios of the two phases, supersaturation of $\alpha$ and the size of $\beta$ can be engineered to reduce aqueous corrosion (see Table III, and Ref. 9). As-Thixomolded material is more corrosion-resistant than die castings. With TTMP coupons, seaside corrosion tests at an aircraft company confirmed the improved corrosion resistance.

\section{PROPERTIES AFTER TTMP}

The mechanical properties of a broad range of hotrolled $\mathrm{Mg}-\mathrm{Al}-\mathrm{Zn}$ alloys were evaluated. Yield strengths above $250 \mathrm{MPa}$ along with elongations of $>6 \%$ emerged. The most attractive combination of properties was found in the $\mathrm{Mg}-6 \mathrm{Al}-(0-1) \mathrm{Zn}$ alloys. AZ31, with $3 \% \mathrm{Al}$ and $1 \mathrm{Zn}$, has insufficient $\beta$ phase to benefit greatly from such processing. AZ91 contains excessive $\beta$ phase, suffering in ductility. AZ70TH was designed for improved ductility while AXJ810-TH benefited from additions of $\mathrm{Ca}$ and $\mathrm{Sr}$ for more creep resistance. 
Table II. Benefit of TTMP plus anneal on formability factors $r$ and $\Delta \boldsymbol{r}^{6,7}$

\begin{tabular}{|c|c|c|c|}
\hline Condition & Texture, MRD & $r$ (stretching) & $\Delta r$ (earing) \\
\hline AZ61 - TTMP & 4.8 & 1.44 & - \\
\hline AZ61 - TTMP + Anneal & 3.5 & 1.12 & 0.18 \\
\hline AZ31-sheet & $8-10$ & 3.0 & 0.30 \\
\hline
\end{tabular}

Table III. Effect of process on corrosion rate in aqueous $\mathrm{NaCl}$ solution ${ }^{8}$

\begin{tabular}{lccc}
\hline Alloy & Process & \% of solids & Corrosion rate, mg/cm $/ \mathbf{d a y}$ \\
\cline { 2 - 3 } AZ91 & Thixomolded & 5 & 0.02 \\
AZ91 & Thixomolded & 25 & 0.01 \\
AZ91 & Die-cast & 0 & 0.03 \\
AM60 & Thixomolded & 0.3 & 0.08 \\
AM60 & Thixomolded & 10 & 0.06 \\
AM60 & THixomolded & 15 & 0.05 \\
AM60 & Die-cast & 0 & 0.11 \\
\hline
\end{tabular}

Table IV. Effect of aging and annealing on TTMP AZ61

\begin{tabular}{|c|c|c|c|c|}
\hline Condition & Yield strength, MPa & UTS, MPa & Elongation, $\%$ & Texture, MRD \\
\hline As-Thixomolded & 140 & 240 & 9 & 1.8 \\
\hline $\mathrm{TTMP}+$ aging $2 \mathrm{~h} / 250^{\circ} \mathrm{C}$ & $326-343$ & $378-380$ & 8 & 4.8 \\
\hline $\mathrm{TTMP}+$ annealing $10 \mathrm{~min} / 285^{\circ} \mathrm{C}$ & 250 & 312 & 15 & 3.5 \\
\hline
\end{tabular}

Table V. Benefit of Thixomolding and TTMP on fatigue strength and toughness of AZ61 ${ }^{9}$

\begin{tabular}{lcc}
\hline Process & Fatigue limit at $\mathbf{1 0}^{\mathbf{6}}$ cycles, MPa & Fracture toughness, MPa mo.5 $^{\mathbf{0}}$ \\
\cline { 3 - 4 } Die-cast & 50 & - \\
As-Thixomolded & 75 & 16 \\
TTMP & 125 & 30 \\
TTMP + anneal & 150 & 28 \\
\hline
\end{tabular}

During TTMP of AZ61, the vol.\% of 2 nd phase $\beta$ is increased from $4 \%$ to $7.6 \%$, by precipitating fine $(0.2 \mu \mathrm{m}$ to $<0.7 \mu \mathrm{m})$ particles within the grains. $\beta$ particle density within the grains increases by $240 \%$. This increase of vol.\% and decrease of interparticle distance boosts the strength, as seen in Table III. The majority of the microstructure contains a high density of dislocations and a reduced grain size of $0.7 \mu \mathrm{m}$, both factors adding to its strength. The larger asThixomolded $\beta$ particles deform during hot rolling with no sign of cracking.

Subsequent annealing leads to complete recrystallization with improved ductility and decreased texture (Table IV).
The benefits of TTMP and annealing on fatigue strength and toughness are demonstrated in Table V. Reduction of porosity and grain size are the contributors.

TTMP was adopted to hot pressing of AM70 (Table VI). Strength was increased as \% reduction was increased from $11 \%$ to $41 \%$. Strengthening benefited from the intragranular $\beta$ and dislocation content seen in Fig. 4.

Another demonstration of hot formability of TTMP AZ61 was performed on the GM gas bulge test, with the results listed in Table VII. Required pressures and time were less for the $\mathrm{Mg}$ alloy. 
Table VI. Effect of TTMP by hot pressing at $300^{\circ} \mathrm{C}$ on the strength of AM70

\begin{tabular}{lcccc}
\hline Condition & Yield strength, MPa & & Ultimate tensile strength, MPa & Elongation, \% \\
\cline { 2 - 2 } As-Thixomolded & 140 & & 273 & 15 \\
$11 \%$ Reduction & 172 & 305 & 16 \\
$23 \%$ Reduction & 214 & 312 & 12 \\
$41 \%$ Reduction & 248 & 401 & 16 \\
\hline
\end{tabular}

Table VII. Comparison of bulge tests on Al-5182 alloy and TTMP AZ61 ${ }^{11}$

\begin{tabular}{|c|c|c|c|c|}
\hline Alloy & Temperature, ${ }^{\circ} \mathbf{C}$ & Bulge height, mm & $\underline{\text { Pressure needed, MPa }}$ & Time needed, s \\
\hline $\mathrm{Al}-5182$ & 255 & 22 & 4.0 & 8 \\
\hline Mg-AZ61-TTMP & 255 & 18 & 2.2 & 4 \\
\hline
\end{tabular}

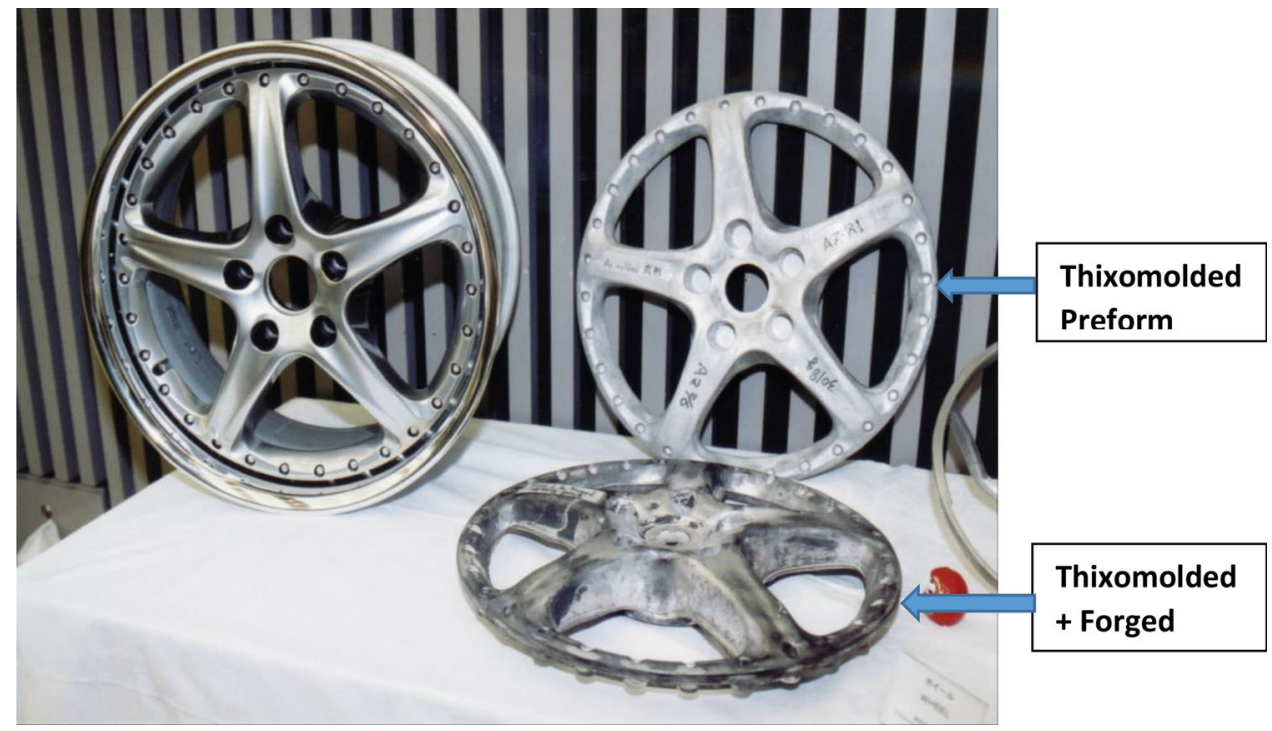

Fig. 7. Auto wheel Thixomolded and forged by Mazda and Japan Steel Works.

As a measure of scalability, Mazda and Japan Steel Works (the major Thixomolding machine producer) collaborated on a trial for an auto wheel that had been Thixomolded on a unit with 1600 ton clamping capacity and then forged (Fig. 7).

\section{COMMERCIAL APPLICATIONS OF REFINED $\beta$ PHASE AND LOW POROSITY}

Thixomolding is now practiced in Asia, United States and Europe. More than 550 Thixomolding machines have been sold by the principal machine builder, Japan Steel Works. Some of the commercial parts are featured in Fig. 8. Electronic/communication parts, for example, lap-top covers at millions/ year, were the first to emerge. Then, auto, sports and hand-tool markets developed.
Parts are molded in complex 3D net shapes in less than a minute cycle time; not requiring machining. Thicknesses down to $0.6 \mathrm{~mm}$ can be molded to tight dimensional tolerances. "Green" environmental friendliness with no open melts and no $\mathrm{SF}_{6}$ cover gas has proven to be attractive, as has design ability to combine multiple parts into one part. All parts and scrap are fully recyclable at a value of about $33 \%$ of virgin stock.

As to TTMP applications, the first is in the biomedical field, as lightweight knee braces (Fig. 9).

\section{FUTURE POTENTIAL FOR PROCESS DESIGN}

Integration of the molding and thermomechanical processing steps into one manufacturing cell could save time, energy and costs. One candidate machine 


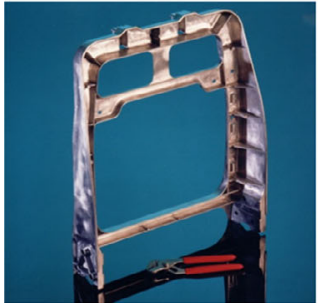

Auto

Seat Backs

Steering Column Brackets

Mirror Parts \& Brackets

Lazy Susan Bins

Foldable Car Tops

Windshield Wiper Boxes

Lift Gate Mechanisms

Gear Shift Boxes

Brackets for Trucks

Electronic boxes

Child Seats

\section{Sporting Goods}

Oakley Sun Glasses

Gun Scopes

Fishing Reels

Snow Board Clamps

Motorcycle Wheels

"Go-Cycle" Bicycle

LED Maglites

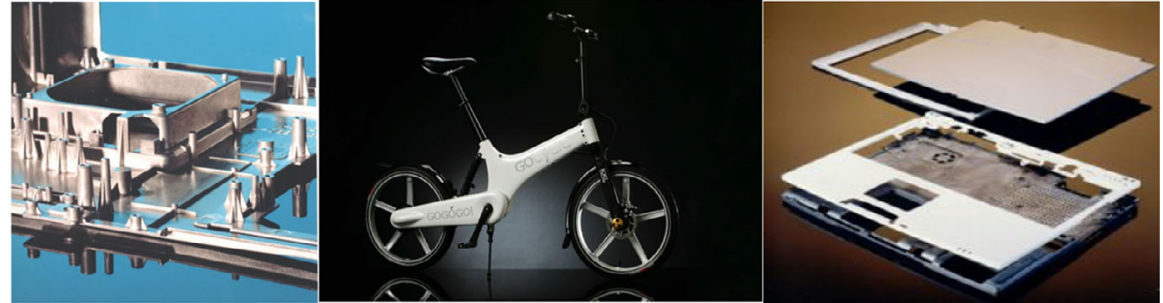

Electronic/Communication

Lap-top Computers

Cell Phones

Digital Projectors

Digital Cameras

Cam Corders

TV Surrounds

Walkman

“Dog Tag” MP3 Player

Check Sorters

Defense Detectors

Radar Detectors

\begin{tabular}{l} 
Hand Held Tools \\
\hline Drills \\
Saws \\
Chain Saws \\
Nailers
\end{tabular}

Fig. 8. Thixomolded commercial parts.

(a)

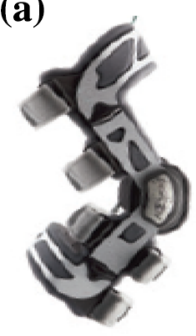

Fig. 9. Commercial lightweight knee brace using TTMP AM60. (Reprinted from Ref. 2). (a) Knee brace and (b) EBSD micrograph of 2- $\mu \mathrm{m}$ grain size with yield strength of $250 \mathrm{MPa}$, fatigue strength of $150 \mathrm{MPa}$, toughness of $28 \mathrm{MPa} \mathrm{m} \mathrm{m}^{1 / 2}$ and texture of $3.5 \mathrm{MRD}$.

might be integrated to inject and locally hot press with the same clamp-end mechanism, using the latent heat of the newly injected metal. Then, the injected/deformed part might be athermally aged to afford the desired 2nd phase/dislocation array. Powder corrosion-resistant coating and baking could be integrated into the final step of cooling.
The product would be finished high strength structural $\mathrm{Mg}$ parts with an optimized 2nd phase $\beta$ microstructure and no porosity. Higher tonnage Thixomolders with hot nozzles will afford larger parts and assemblies. Finally, process modeling ${ }^{10}$ and ICME will enhance the process.

\section{CONCLUSION}

Alloy design and processing design of 2 nd phase $\beta$ phase in $\mathrm{Mg}$ alloys can enable the following:

a. Restraining grain growth.

b. Inserting intragranular dispersions.

c. Multiplying intragranular dislocations.

d. Randomizing texture without rare earth additions.

e. Moderating corrosion couple arrays.

Using these mechanisms, yield strength, fatigue strength, ductility, toughness, formability and corrosion resistance can be engineered in commercial low-cost Mg alloys. 
The other critical 2nd phase, porosity, can be reduced by sub-solvus molding and thermomechanical processing, with benefits to fatigue strength, ductility, toughness and corrosion resistance.

\section{ACKNOWLEDGEMENTS}

The authors are pleased to honor the support of NSF Award No. DMR 1121053 and NSF STTR Award No. 0847198 (Program Manager, Dr Prakash Balan) and graduate school support from The University of Michigan and University of California Santa Barbara.

\section{REFERENCES}

1. R. Decker, D. Dawson, R. Carnahan, and S. LeBeau, Thixomolding ${ }^{\circledR}$-High Integrity Casting of Light Weight Components, ed. D. Twarog, D. Apelian, and A. Luo (Mount Laurel: NADCA Pub., 2016), pp. 307-361.

2. R. Decker, S. LeBeau, T. Berman, V. Miller, V. Jones, J. Pollock, T. Moskovich, and B. Bronfin, in Magnesium Technology (TMS, 2017), p. 235.

3. R. Decker, J. Huang, S. Kulkarni, S. LeBeau, and R. Vining, US Patent No. 9,017,602 B, April 28, 2015.
4. T. Berman, T. Pollock, and J. Jones, Metal. Mater. Trans. A 47A, 3125 (2016).

5. V. Miller and T. Pollock, Metal. Mater. Trans. A 47A, 1854 (2016).

6. T. Berman, W. Donlon, T. Miller, R. Decker, J. Huang, T. Pollock, and J. Jones, in Proceedings of the 9th International Conference Mg Alloys and their Applications, ed. by W. Poole and K. Kainer (ICMAA, 2012), p. 571.

7. T. Berman, W. Donlon, T. Miller, Decker, J. Huang, T. Pollock, and J. Jones, in Magnesium Technology (TMS, 2012), p. 339.

8. R. Buzolin, H. Dieringa, C. Blawert, H. Frank, C. Mendis, A. Lohmuller, K. Kainer, and N. Hort, in Magnesium Technology (TMS, 2017), p. 381.

9. Z. Chen, J. Huang, R. Decker, S. LeBeau, L. Walker, O. Cavin, T. Watkins, and C. Boehlert, Metal. Mater. Trans. A 42A, 1386 (2011)

10. V. Miller, T. Berman, I. Beyerlein, and T. Pollock, in Magnesium Technology (TMS, 2016), p. 257.

11. P. Cain, Interlaken Technology Corporation, Private Communication.

Publisher's Note Springer Nature remains neutral with regard to jurisdictional claims in published maps and institutional affiliations. 